\section{ACTIUALDADDE SPEEDYGONZALES}

Mareo Antonio Murillo

\section{El llamado "ratón más veloz de México" será el sujeto de mi atención, pues me interesa la lectura que lleva implícita: los problemas ra- ciales y la economía mexicana frente a la es- tadounidense.}

D esde sus inicios, el cómic ha tenido prácticamente la misma intencionalidad con que fue concebido: ser un objeto de divertimento para el público lector $y$, a su vez, ejercer una crítica a la sociedad (recordemos la litografía satírica de Napoleón Bonaparte del caricaturista inglés James J. Gillray [1800] y los llamados Cuentos en imágenes [1829] de Töpfer). En ese sentido, los mejores cómics aspiran a ser retratos de la sociedad o del grupo poblacional al que se dirigen. Por su parte, el dibujo animado, hijo del cómic y del cine, posee en esencia las características antes mencionadas.

Con el auge del cómic y las caricaturas durante el siglo xx, Estados Unidos construyó una imagen icónica del espíritu norteamericano, a través de algunos de sus personajes emblemáticos: Supermán,
Capitán América, Mickey Mouse. México, sin embargo, no se quedó atrás y le otorgó su sello personal al cómic hacia mediados del siglo xx. Al respecto, Armando Bartra comenta:

Con pocos recursos y sin el peso de la academia ni el lastre de la tradición, la imaginería monera mexicana es culturalmente irresponsable. Pero también es ligera, desparpajada, libérrima. Frente a la mesurada armonía de la historieta europea y hasta del cómic norteamericano, nuestros monitos resultan excesivos, delirantes; producto de una creatividad desmecatada donde las convenciones del súper-yo cultural, que encorsetan a los primermundistas, dejan paso a los desfajados impulsos del inconsciente tumultuario (2001).

Ciertamente, la cultura popular mexicana está más asociada al relajo y al humor que a lo serio; esto tal vez explique que entre las publicaciones de cómics nacionales hayan destacado aquellas cuya trama apunta a la comedia y la sátira: Los Súper-locos (1942), Memín Pinguín (1943), La familia Burrón (1952), Hermelinda Linda (1965), por citar algunos. De cualquier modo, no hay que olvidar que el mercado del cómic nacional ha estado abierto a otro tipo de publicaciones: las de héroes como Kalimán (1963); aquellas con sentido educativo que realizó la desaparecida editorial Novaro, como Joyas de la mitología y Vidas ejemplares, sin olvidar aquellas de temas eróticos y melodramáticos, como el Libro vaquero (1978). Con todo lo dicho, me gusta pensar que existen tres formas distintas en que los mexicanos nos relacionamos con el mundo del cómic o de las caricaturas: el esbozo del mexicano por el mexicano mismo, la invención de personajes susceptibles de adaptarse a nuestro imaginario, $y$ la caricaturización del mexicano por el extranjero.

El primer rubro es donde convergen las creaciones realizadas por nuestros caricaturistas. El segundo reúne personajes como el Pato Donald, creados para que los lectores de países subdesarrollados identifiquen su situación socioeconómica con ellos. Sobre este punto resulta interesante dar un vistazo al trabajo realizado por Dorfman y Mattelart: "en América Latina el más popular es Donald, que aparece como propagandista de la revista [... Nosotros tendemos a identificarnos con el imperfecto Donald, a merced de las dádivas superiores, del destino como padre, que con Mickey, que es el amo de ese mundo, el espía 
que Disney nos envía”. En el último punto recaerían personajes creados con base en la exotización: Pancho Pistolas de Disney, y Speedy Gonzales de la Warner Brothers son algunos de ellos.

El llamado "ratón más veloz de México" será el sujeto de mi atención, pues me interesa la lectura que lleva implícita: los problemas raciales y la economía mexicana frente a la estadounidense. Dos situaciones que, a raíz de la llegada de Donald Trump a la silla presidencial, se han acrecentado y son totalmente vigentes en nuestras sociedades. Antes de entrar en materia ofrezco algunos datos: Speedy Gonzales debutó en el año de 1953 con el episodio "Cat-Tails For Two", pero no fue sino hasta 1955, con un cortometraje que llevaba como título su nombre y que fue premiado con un Óscar, cuando tomó la forma en que lo conocemos actualmente. Su némesis era Silvestre, pero hacia mediados de la década de los sesenta el Pato Lucas pasó a ocupar el sitio del gato, momento en que la caricatura se entibió en cuanto a contenido social.

Érase una vez en un little time pueblo, un ratoncito muy veloz y muy enamorado al que llamaban "Speedy Gonzales”, esta es su historia y lo que pasó cuando su novia Rosita se fue y dice más o menos así:

Speedy Gonzales, Kumbia All Starz

El nombre Speedy Gonzales es una alegoría del espacio fronterizo entre México y Estados Unidos. Se forma a partir de dos idiomas distintos: el nombre de pila es una especie de made in USA y a la vez
La crítica vertida en Speedy Gonzales respondió en su momento al despunte de emigrantes mexicanos hacia los

Estados Unidos en busca de trabajo, debido en parte al Programa Bracero (1942-1964), que tuvo la finalidad de suplir temporalmente a los trabajadores estadounidenses.

un adjetivo calificativo que señala la mejor cualidad del ratón: su velocidad; por otra parte, el apellido de origen español es un patronímico derivado de Gonzalo. Sin embargo, está deliberadamente mal escrito ("González" sería la forma actual correcta), remitiendo a las comunidades chicanas que habitan las fronteras; es decir, aquellas poblaciones mexicanas que han modificado su forma de hablar y escribir el español, combinándolo con la lengua inglesa. Lo fronterizo también se refleja en el maquetado de los espacios en donde el ratón realiza sus mejores hazañas: la frontera entre México y Estados Unidos. A México se le dibuja como un pueblo pequeño construido en el desierto, con casas de adobe, uniformes, y una que otra cantina; mientras que a Estados Unidos se le detalla como un lugar industrializado, el sitio donde hay verdadera actividad económica. Por ello, en no pocos episodios surge entre los ratones la necesidad de obtener queso (el producto económico) para sobrevivir, trama central en el ya mencionado capítulo Speedy Gonzales (1955). En cuanto al dibujo del queso, más que producto lácteo, pareciera pepita de oro.

En ese sentido, México se muestra como un país subdesarrollado. El robo de queso representa un peligro para el país vecino, un peligro que el gato Silvestre intenta detener cuando ve que los recursos del país están siendo robados por "El ratón más veloz de México". En Silvestre subyace una crítica a la incompetencia de los agentes fronterizos o de las autoridades estadounidenses para controlar adecuadamente la migración. Y es que Speedy, con su velocidad, entra y sale de Estados Unidos a su antojo, siempre en la ilegalidad, sin que nadie pueda hacer algo por detenerlo.

La crítica vertida en Speedy Gonzales respondió en su momento al despunte de emigrantes mexicanos hacia los Estados Unidos en busca de trabajo, debido en parte al Programa Bracero (19421964), que tuvo la finalidad de suplir temporalmente a los trabajadores estadounidenses. Pero basta observar detenidamente algunos episodios y reflexionar para darse cuenta de que las caricaturas del veloz ratón no sólo enmarcan los sucesos de las décadas 1940-1960, sino que también pueden aplicarse a la ya larga relación "amistosa" entre México y Estados Unidos. Cualquier episodio podría perfectamente representar la Guerra de Intervención, o bien la relación con los últimos presidentes que han habitado la Casa Blanca.

Por mi parte, el queso me recuerda el Tratado de Libre Comercio de América del Norte (TLCAN). Según Donald Trump, con su puesta en marcha en 1994, Mé- 


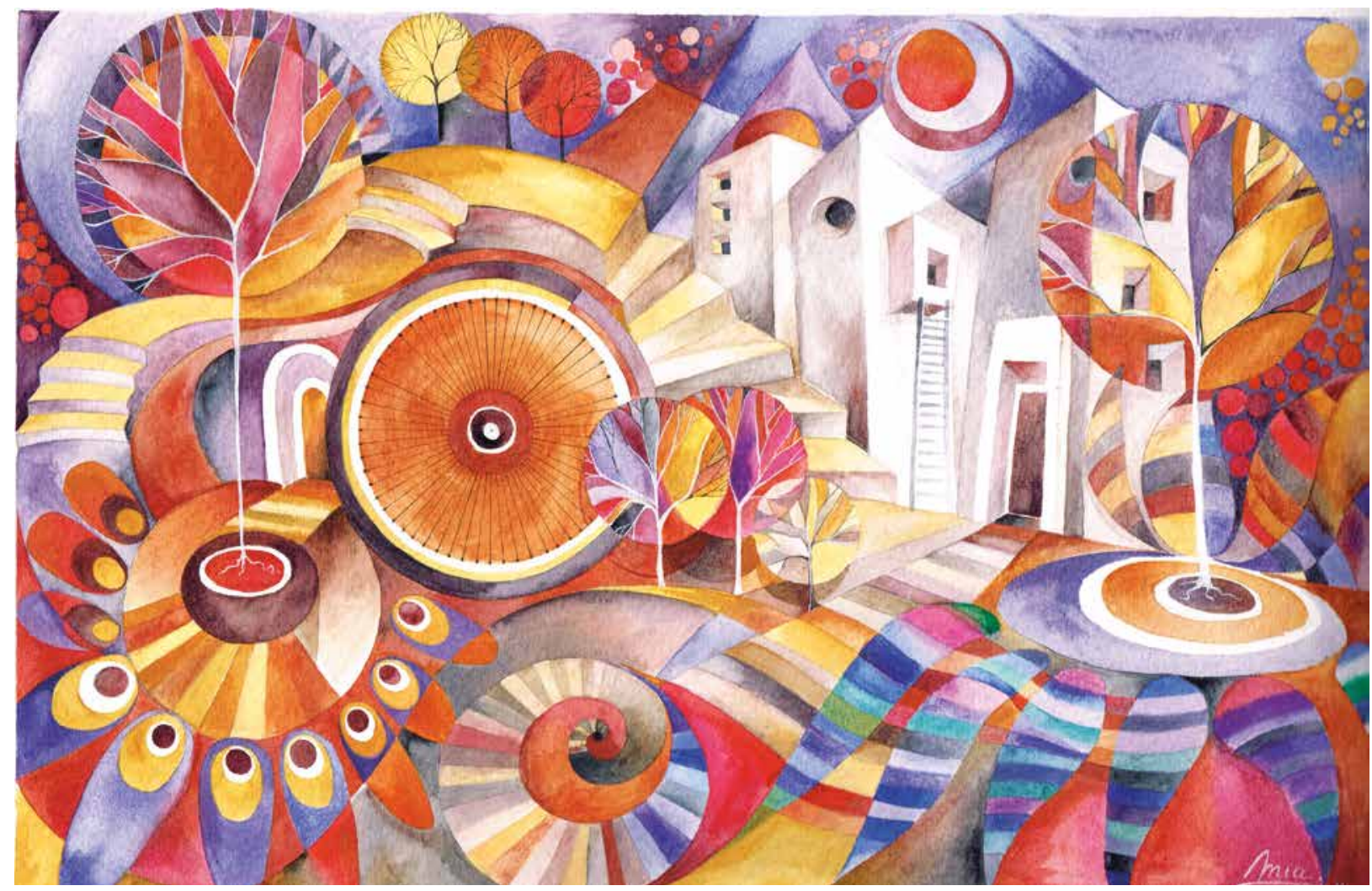

Ciclos. De la serie Ciclos

xico resultó ser el más beneficiado de los tres países que lo firmaron y los ciudadanos estadounidenses han visto cómo, a lo largo de 23 años, fuentes de empleo, empresas y capital han sido arrebatados de sus manos. Así, interpreto la incompetencia de Silvestre como metáfora de la urgencia que tiene Trump de contratar más agentes fronterizos, agilizar las deportaciones de ilegales e iniciar la construcción de un muro divisorio, acciones que, de hecho, están pensadas para aumentar los índices económicos y de empleos en el sur de Estados Unidos. A más Silvestres, más norteamericanos empleados.

En el universo caricaturesco creado por Warner Brothers, la velocidad de Speedy Gonzales es su rasgo distintivo, pero no es el único personaje que posee dicha característica. El Correcaminos tam- bién la usa para escapar de su antagonista, el Coyote. Sin embargo, la velocidad del Correcaminos se asocia a la astucia y la inteligencia (esquivar las trampas del Coyote) y, si se quiere, la suerte (un camión atropella al Coyote cuando está a punto de atraparlo), mientras que la velocidad de Speedy Gonzales tiene otra connotación: lo convierte en una especie de héroe cercano a Robin Hood, que ayuda al más débil a costa de infringir la ley estadounidense. No es, entonces, una rapidez emparentada con valores positivos, pues el robo y el bien ajeno son su fin. En otras palabras, él se hace justicia por mano propia, puesto que en las ciudades fronterizas no hay ley alguna, y si la hay, es mediocre.

Lo indicado con anterioridad, de acuerdo con el blog Ausente en su nota "Se busca: Speedy Gonzales, preferiblemente muerto", ocurre en el episodio "West of the pesos” (1960). Allí Speedy cruza nuevamente la frontera, pero esta vez para salvar a sus amigos ratones que han sido secuestrados por la compañía ACME, para obligarlos a trabajar. Una nueva crítica hacia la vida fronteriza: el uso y abuso de mexicanos para el beneficio de la economía estadounidense, como ocurre cada año con cientos de braceros y demás trabajadores indocumentados. Según el Centro de Investigaciones Pew, hasta 2017 existían 5.8 millones de indocumentados mexicanos ( $52 \%$ del total de inmigrantes sin papeles en Estados Unidos), los cuales estaban expuestos a sufrir racismo por parte de la sociedad, invisibilización ante las autoridades y negación de sus derechos laborales.

Si bien la imagen valiente, solidaria y justiciera de Speedy que se muestra en "West of the 
Pesos" podría verse como un intento de otorgar valores positivos al sujeto mexicano, en los hechos funciona como un personaje más del cómic norteamericano de superhéroes. Esto se nota al revisar el atuendo del ratón: el sombrero charro, la camisa y el pantalón de manta holgados, así como el paliacate rojo remiten a la forma en que los mexicanos se vestían en el siglo XIX. Otra vez el anacronismo entra en juego (el subdesarrollo $v s$. la sociedad industrializada). Además, su piel morena y su baja estatura están allí como parodia de los rasgos indígenas de buena parte de los mexicanos; mientras que el idioma que habla es un español pocho, totalmente diferente al que suele utilizarse en las ciudades fronterizas.

La narrativa de la vida fronteriza conlleva la estereotipación no sólo de Speedy, sino también de los personajes secundarios que enriquecen las tramas de los capítulos. En el episodio "Tobasco Road" (1957), los ratones Pablo y Fernando, en estado alcohólico, recorren el pueblo riñendo con los gatos. Aquí se rescata la idea del mexicano como zángano, ya planteada en los capítulos donde Speedy roba queso para subsistir, y reforzada con la idea del abuso de alcohol entre los mexicanos. Así, los ratones no sólo no trabajan, sino que pasan su tiempo enfiestados, ebrios y, por si fuera poco, alterando el orden público.

En esta misma línea se encuentran las referencias a la marihuana a través de la canción $L a$ cucaracha. Una, según se comenta en el blog Ausente, está contenida en el episodio llamado Gonzales Tamales (1957); la otra en "Mexican Borders" (1962), interpretada por el primo de Speedy, Lento
Rodríguez, "El ratón más lento de México", cuyo tono de voz acentúa la referencia al consumo de droga. Asimismo, en este capítulo es posible ver a Silvestre consumiendo a toda prisa ingentes cantidades de anfetaminas. Una encuesta realizada hacia finales de 2012 por las consultoras Vianovo y GSD\&M, y publicada el 21 de noviembre en El Universal, reveló lo que los estadounidenses pensaban sobre México. De mil personas encuestadas, $50 \%$ tenían una visión desfavorable, ya sea por el crimen organizado, la inmigración ilegal o la pobreza. El $81 \%$ aseguró que las noticias que recibía sobre México estaban relacionadas con las drogas.

El latin lover es otro de los estereotipos recurrentes en los episodios de Speedy; recuerda a los grandes actores de la Época de Oro del cine mexicano: Pedro Infante y Jorge Negrete. En "Gonzales Tamales", por ejemplo, se narra cómo los compadres de Speedy, hartos de que les robe a las novias, contratan a Silvestre para que elimine al competidor. El carácter de latin lover que despliega el ratón está emparentado con la misoginia y el machismo, ofreciendo como mensaje la desigualdad de los géneros y todo lo que implica en nuestra sociedad: desde los micromachismos que aderezan la vida cotidiana de las familias mexicanas, hasta los lamentables feminicidios de los que día con día da cuenta la prensa. En el capítulo llamado "Speedy Gonzales", ante la llegada del roedor, uno de los desesperados ratones dice: "No se preocupen, Speedy Gonzales está enamorado de mi hermana”, mientras que otro replica: "Speedy Gonzales está enamorado de todas nuestras hermanas".
Actualmente ningún canal mexicano emite las aventuras de este peculiar ratón; si queremos verlas será necesario buscar en Youtube o acceder a las páginas de descargas piratas de la red. Las últimas participaciones que tuvo fueron “Bugs Bunny's Howl-oween Special” (1978), "Daffy Duck's Easter Show" (1980), "Bugs Bunny's 3rd Movie: 1001 Rabbit Tales” 1982), "Looney Tunes: Back in Action" (2003), la serie The Looney Tunes Show (2011-2013) y la última: "Looney Tunes Rabbits Run" (2015). También se habla de una próxima película, cuyo protagonista será el mismo Speedy, y que estará producida por Eugenio Derbez y Warner Brothers.

Si bien el ratón mexicano se ha vuelto un personaje secundario al correr de las décadas, los estereotipos raciales siguen vigentes en algunas partes de los Estados Unidos. Con la noticia de la película sobre el ratón mexicano, el productor Dylan Sellers ha manifestado: "En tiempos en que Donald Trump está ganando fama, el mundo necesita a Speedy más que nunca”. Mientras llegan a nuestras pantallas los primeros trailers de la cinta, me entero de que se está renegociando el TLCAN. Espero que dicha reunión, no sea el desarrollo de un capítulo más de Speedy Gonzales: no vaya a ser que nuestro presidente juegue al gato y al ratón, se crea vencedor y festeje mientras el país sigue en las mismas condiciones de miseria. LPyH

\footnotetext{
- Marco Antonio Murillo es maestro en Creative Writing por la Universidad de Texas. Publicó los poemarios Muerte de Catulo y La luz que no se cumple. Actualmente es becario de la Fundación para las Letras Mexicanas.
} 